\title{
Gerenciamento da diferença: relaçóes de poder e limites profissionais no serviço de atendimento móvel de urgência
}

Managing the difference: power relationships and professional boundaries in the mobile emergency care service

La gestión de la diferencia: las relaciones de poder y los límites profesionales en el servicio móvil de emergencia

Isabela Silva Câncio Velloso*; Meiriele Tavares Araujo**; Jéssica Dias Nogueira** Marília Alves****

\section{Resumo}

Enquadramento: Serviço de Atendimento Móvel de Urgência (SAMU), um serviço do Sistema de Saúde Brasileiro, é influenciado por determinantes económicos, políticos e simbólicos, tornando-se um sistema de interesses e uma arena de conflitos.

Objetivos: Compreender como as práticas de poder configuram as relações e os limites profissionais no SAMU de Belo Horizonte, Brasil.

Metodologia: Trata-se de um Estudo de Caso qualitativo que se utilizou do referencial pós-estruturalista.

Resultados: Sob a ótica dos limites profissionais e das delimitações territoriais no trabalho do SAMU, percebe-se as dificuldades para reconhecerem o grupo enquanto equipa de trabalho, enquanto os seus discursos reforçam a histórica dominação da classe médica sobre os demais profissionais.

Conclusão: Para os profissionais do SAMU um dificultador é identificar e compreender os tênues limites entre o seu espaço de trabalho e o dos outros, já que o seu espaço de atuação corresponde a todo território da cidade e tentar delimitá-lo é um desafio maximizado pela fragmentação dos serviços de saúde e dos conflitos existentes, os quais favorecem ações individualistas prejudiciais à proposta de integração do sistema de saúde.

Palavras-chave: serviços médicos de emergência; equipe de busca e resgate; prática profissional; relações interprofissionais.

\begin{abstract}
Background: The Mobile Emergency Care Service (Serviço de Atendimento Móvel de Urgência - SAMU), which is provided by the Brazilian Health System, is influenced by economic, political and symbolic determinants, making it a system of interests and an area of conflicts.

Objectives: To understand how power practices shape relationships and professional boundaries at the SAMU of Belo Horizonte, Brazil. Methodology: This is a qualitative case study based on the poststructuralist framework.

Results: From the perspective of professional and territorial boundaries in the work performed at the SAMU, there are difficulties in recognising the group as a work team, while its discourses reinforce the historical dominance of the medical profession over the other professions.

Conclusion: SAMU professionals struggle to identify and understand the thin line between their workspace and the workspace of others as their area of activity corresponds to the city as a whole. Setting its limit is a huge challenge due to the fragmentation of health services and the existing conflicts, which promote individualistic interventions that undermine the proposal to integrate the health care system.
\end{abstract}

Keywords: emergency medical services; search and rescue team; professional practice; interprofessional relations.

\footnotetext{
* Doutora em Enfermagem. Professora Adjunto do Departamento de Enfermagem Aplicada, da Escola de Enfermagem da Universidade Federal de Minas Gerais (UFMG) CEP 30130-100, Belo Horizonte, Minas Gerais, Brasil [isacancio@gmail.com]. Morada para correspondência: Av. Alfredo Balena, 190, CEP 30130-100. Belo Horizonte, Minas Gerais, Brasil.

Av. Alfredo Balena, 190, CEP 30130-100. Belo Horizonte, Minas Gerais, Brasil.
** Doutora em Enfermagem. Professora Adjunta do Departamento de Enfermagem Aplicada da Escola de Enfermagem da Universidade Federal de Minas Gerais (UFMG), CEP 30130-100, Belo Horizonte, Minas Gerais, Brasil. [enfaraujo@gmail.com].

*** Académica do Curso de Graduaç̃o em Enfermagem da Fscola de Enfermagem da UFMG. CEP 30130-100. Belo Horizonte, Minas Gerais, Brasil [jessv10 60@ hotmail.com].

**** Doutora em Enfermagem. Professora Titular do Departamento de Enfermagem Aplicad da Escola de Enfermagem da UFMG. Av. Alfredo Balena, 190, CEP 30130-100, Belo Horizonte, Minas Gerais, Brasil [marilix@enf.ufmg.br].
}

\section{Resumen}

Contexto: El servicio móvil de emergencia (SAMU), un servicio del sistema de salud de Brasil, se ve influido por factores económicos, políticos y simbólicos, lo que le convierte en un sistema de intereses y un escenario de conflictos.

Objetivo: Comprender cómo las prácticas de poder dan forma a las relaciones y los límites profesionales en el SAMU de Belo Horizonte, Brasil.

Metodología: Estudio de caso cualitativo que utilizó el marco posestructuralista.

Resultados: Desde la perspectiva de los límites profesionales y los límites territoriales en el trabajo del SAMU, se observan dificultades para reconocer al grupo como un equipo de trabajo, mientras que sus discursos refuerzan el dominio histórico de la profesión médica con respecto a otros profesionales.

Conclusión: Para estos profesionales es un factor de complicación identificar y comprender las tenues fronteras entre el espacio de trabajo y el de los otros, ya que su espacio se corresponde con el territorio de toda la ciudad, y tratar de delimitarlo es un desafío que se ve aumentado por la fragmentación de los servicios sanitarios y de los conflictos, los cuales favorecen las acciones individualistas que perjudican la propuesta de integración del sistema de salud.

Palabras clave: servicios médicos de urgencia; personal de rescate; práctica profesional; relaciones interprofesionales.

Recebido para publicação em: 28.08 .12

Aceite para publicação em: 30.04 .14 


\section{Introdução}

A organização e divisão do trabalho podem ser entendidas como um processo social de contínuas negociações, onde os sujeitos envolvidos estão continuamente empenhados na definição, no estabelecimento, na manutenção e na renovação das tarefas quotidianas, bem como nos relacionamentos que esses processos abarcam. Entretanto, essas negociações não são incondicionais, uma vez que as interações sociais são configuradas por diversos elementos, tais como as relações de poder vivenciadas pelos indivíduos e as características do próprio contexto em que elas ocorrem (Freidson, 1976; Allen, 2000).

O trabalho em saúde surge como um cenário particularmente rico, no qual pode-se analisar o universo do trabalho e das profissões, além da própria natureza da sua estrutura, considerando o seu dinamismo, o elaborado ambiente tecnológico, a incorporação de várias interfaces sociais como setores público, privado, filantrópico e voluntariado. Esses fatores também implicam uma complexa divisão de trabalho que envolve diversas profissões, ocupações, sistema de gestão e tecnologias (Allen \& Pilnick, 2005).

Quando observamos a situação do Serviço de Atendimento Móvel de Urgência (SAMU), em Belo Horizonte, Minas Gerais, Brasil, como algo relativamente novo no contexto da assistência à saúde, julga-se necessário uma análise da sua organização do trabalho, bem como da demarcação de territórios profissionais, uma vez que, com essa análise, é possível reconhecer fragilidades e potencialidades do Serviço.

A proposta de implantação do SAMU em Belo Horizonte surgiu a partir da necessidade de atender à nova legislação Federal de atenção às urgências, a Portaria $n^{0} 2.048$ (Portaria no 2.048/GM-MS de 5 de Novembro, 2002). O modelo do SAMU brasileiro é um mix do modelo Francês, que possui profissionais de saúde especializados para esse atendimento e a presença obrigatória do médico no suporte avançado, e do modelo Americano, que possui técnicos em emergências médicas (Emergency Medical Technician) ou paramédicos treinados para esse tipo de atendimento. Desse modo, as atribuições de cada profissional no contexto brasileiro foram organizadas de acordo com referências internacionais que diferem muito do contexto ético, legal e de competências dos profissionais de saúde brasileiros.

Entretanto, pelas próprias características dos serviços de atendimento pré-hospitalar, é importante considerar que, no trabalho do SAMU, as relações profissionais assumem um caráter multidirecional, uma vez que se trata de um Serviço que presta assistência em caráter transitório, ou seja, não é o destino final da pessoa atendida, mas destina-se a encaminhar o paciente a esse destino. A identificação do melhor destino para o paciente também se constitui num elemento de constantes negociações e definições de limites territoriais, tanto dentro do próprio SAMU, como em relação aos níveis assistenciais da rede de serviços de saúde do município.

O objetivo deste estudo foi compreender como as práticas de poder configuram as relações e os limites profissionais no SAMU da cidade de Belo Horizonte.

\section{Enquadramento}

A produção de saúde num determinado sistema envolve, além do contingente de recursos humanos, o gerenciamento do aparato tecnológico, de informação e da própria estrutura organizacional. Nesse complexo cenário, a divisão de tarefas entre os diferentes trabalhadores não se delineia obedecendo a um critério de qualificação técnica para o desempenho de determinada função na estrutura organizacional. Também são considerados elementos como contexto social, regulamentações profissionais e normas. Entretanto, as regras adotadas por diferentes grupos são dinâmicas, o que reflete o contínuo movimento de mudança da estrutura do cuidado em saúde, da evolução tecnológica e de novas formas de trabalho. Tal dinamismo proporciona a criação de novas regras, ao mesmo tempo em que outras, ainda que obsoletas, são mantidas (McKee, Dubois, \& Sibbald, 2006).

Nos últimos anos, o foco na contenção de custos e gastos nos serviços de saúde levou à introdução de novas formas de organização e gestão. Isso ocasionou profundo impacto na organização social do trabalho, desafiando a linha tradicional de demarcação de fronteiras profissionais e sinalizando para 0 desenvolvimento de novas regras e modalidades de trabalho. Além disso, essas mudanças têm sido reforçadas por ideologias de cidadania que apontam para a necessidade de um redimensionamento, nos 
serviços de saúde, das relações entre profissionais e clientes/pacientes/usuários, bem como pela introdução de novas tecnologias que modificam o ambiente de trabalho provocando mudanças na sua divisão e nas suas práticas (Allen \& Pilnick, 2005).

Nesse contexto, percebe-se a importância da participação interativa e integrativa dos diversos elementos, tais como recursos humanos, aparato gerencial e tecnológico, entre outros, na constituição da sua estrutura organizacional de trabalho. É importante considerar que as constantes mudanças sociais se têm refletido nas organizações de um modo geral, inclusive nas organizações de saúde, as quais precisam reconhecer as novas exigências para serem capazes de se adaptarem às novas demandas dos usuários dos sistemas de saúde (Cruz \& Ferreira, 2012).

A organização e a divisão do trabalho podem ser entendidas como um processo social de contínuas negociações que se associam à manutenção e renovação das tarefas quotidianas, bem como nos relacionamentos que esses processos abarcam. As negociações tendem a florescer de forma mais expressiva quando se está diante de condições de mudanças, incertezas e ambiguidades, desentendimentos, diversidades ideológicas, novidades e inexperiência (Allen, 2000).

Em cada uma dessas negociações há interesses a serem defendidos, o que faz com que limites sejam definidos e redefinidos constantemente num continum de relações de poder, o que interfere diretamente no processo de trabalho do SAMU. É nesse contexto relacional, que se desenvolverão as relações de força, que, na verdade, podem ser interpretadas como relações de poder. Nesse sentido, é válido considerar que o poder não tem centro, constitui-se como um sistema em rede, fortalecido pelas suas ligações, traduzidas pelas suas relações culturais. Cada um dos elos da cadeia social produz, reproduz e transforma 0 poder (Foucault, 2008).

\section{Metodologia}

O presente artigo é parte da tese de doutoramento intitulada "Configurações das relações de poder no Serviço de Atendimento Móvel de Urgência", um estudo de caso qualitativo, realizado no SAMU de Belo Horizonte. Optou-se por uma pesquisa qualitativa considerando que, a partir de descrições pormenorizadas sobre uma realidade específica, pretende-se superar conceções iniciais, oferecendo base para descrições e explicações de contextos específicos (Miles \& Huberman, 1994).

A amostra foi composta por 31 trabalhadores - 5 médicos, 11 enfermeiros, 7 auxiliares de enfermagem e 8 condutores. A seleção deu-se por conveniência, considerando-se critério de inclusão o aceite em participar voluntariamente no estudo. Na análise dos dados, os sujeitos são identificados pelas letras iniciais de sua categoria profissional (enfermeiro - E, auxiliar de enfermagem - AE, médico - $\mathrm{M}$ e condutores - $\mathrm{C}$ ) e enumerados consecutivamente, de acordo com cada categoria. Os dados foram colhidos de março a maio de 2010, utilizando-se roteiro de entrevista semiestruturada, com as seguintes questões: $\mathrm{O}$ que o levou a optar por trabalhar no SAMU? Qual a sua perceção sobre as relações entre os profissionais da equipa do SAMU? Como são as relações entre a equipa do SAMU e os profissionais de outras Unidades da rede de saúde? Como você percebe a estrutura organizacional do SAMU, considerando as formas de gestão e estrutura hierárquica? As entrevistas foram gravadas em equipamento Multimedia Player 4 e transcritas na íntegra.

Os dados foram submetidos à análise de discurso, uma vez que esse tipo de análise permite a problematização de evidências e a explicação do seu caráter ideológico, bem como o reconhecimento do encobrimento de formas de dominação política expressas no seu conteúdo (Fairclough, 2006; Capelle, Melo, \& Gonçalves, 2003). Para a operacionalização dos dados, foram seguidos os passos de ordenação dos dados, classificação dos dados e análise final (Minayo, 2004). O projeto de pesquisa seguiu os preceitos da Resolução 196/96 para pesquisas envolvendo seres humanos (Resolução no 196 de 10 de Outubro, 1996), tendo sido aprovado pelo Comité de Ética em Pesquisa da Universidade Federal de Minas Gerais, sob parecer número 105/2009 e todos os participantes do estudo assinaram o Termo de Consentimento Livre e Esclarecido.

\section{Resultados e Discussáo}

No período da implantação do SAMU em Belo Horizonte, a atuação conjunta de profissionais 
do próprio SAMU e de socorristas do Corpo de Bombeiros no atendimento pré-hospitalar era fator de conflitos, uma vez que que as atribuições de cada ator não estavam claramente definidas. Isso era reflexo da necessidade de definição dos espaços de cada um desses serviços, Resgate e SAMU, num cenário onde ambos, possivelmente, desconhecessem as reais possibilidades de complementaridade das suas ações, diante de muitas dúvidas sobre o seu futuro.

$\mathrm{O}$ relato a seguir é uma referência ao período de implantação do SAMU na cidade: No resgate, eu brigava com o bombeiro, media força. Tipo, assim, eu brinco que era igual cachorro demarcando território. Ele fez xixi, eu ia e fazia atrás, porque a outra palavra foi minha. (M4).

Este relato mostra como, durante o processo de implantação do SAMU, a forma de organização do processo de trabalho do Serviço recém-criado deixava margem para uma forte luta por delimitação de espaços. Isso aponta um cenário micropolítico, onde o que está colocado em cena, não é apenas a arena de atuação profissional, mas a representação de um serviço que procura o seu reconhecimento através das suas práticas. As práticas vêm imbuídas de um revestimento heroico de atendimento, uma vez que este serviço é implantado sobre o discurso de ser um elo entre os demais serviços existentes na rede e possuir a responsabilidade de melhoria de acesso aos serviços de urgência e emergência bem como sobrevida dos usuários.

Observa-se que há uma luta por supremacia no contexto da atenção pré-hospitalar, na qual não é clara a convergência de esforços em função de um objetivo comum. Embora o relato seja uma referência à história de implantação do SAMU em Belo Horizonte, ainda há, na estrutura atual do Serviço, uma constante luta por demarcação de territórios. Essa luta envolve, além dos seus próprios trabalhadores, dentre os quais há intensas buscas por espaço, os trabalhadores de outros níveis assistenciais da saúde que, mesmo alocados em outros pontos da estrutura do sistema de saúde, se relacionam com o SAMU.

Entretanto, é importante considerar que a divisão do trabalho deve produzir solidariedade social. Quando isso não acontece, o que se tem não é uma divisão de trabalho, mas uma simples diferenciação de tarefas, onde o indivíduo se limita à sua tarefa, isolase na sua atividade especial e não sente que outros indivíduos trabalham junto com ele, na mesma tarefa. A solidariedade é um notável efeito da divisão do trabalho, à medida que as funções divididas têm o seu rendimento maximizado, além do que, na solidariedade da divisão do trabalho, os indivíduos completam-se mutuamente já que, isolados, todos são incompletos. Embora seja reconhecida a utilidade económica da divisão do trabalho, ela é superada pela sua importância no estabelecimento de uma ordem social e moral sui generis (Durkheim, 2008). Assim, observa-se que ainda é precoce discutir a questão da solidariedade no processo de trabalho do SAMU, uma vez que o que aparece nos discursos, de forma mais evidente, são situações em que o próprio respeito entre os profissionais é questionado, bem como a compreensão sobre a real finalidade das atividades do Serviço, como relatado no trecho de discurso que se segue:

Na minha experiência, eu acho uma falta de respeito, às vezes mútua, sabe, do médico da regulação com o pessoal da assistência básica e UPA (Unidade de Pronto Atendimento). E da UPA, também, com a gente. Porque, é... eu entendo assim, chega uma unidade básica, uma unidade avançada no setor, e se a pessoa soubesse como que funciona, ela se prontificaria a liberar o mais rápido possivel aquela ambulância, porque sabe que vai precisar dela pra outras ocorrências, e tudo. No entanto, eles interpretam que você tá levando é trabalho prá eles. Então, assim, eu sinto muita falta de respeito, mas é mútua. (M3).

O entrevistado coloca em questão a falta de conhecimento de profissionais de outros serviços de saúde sobre o trabalho do SAMU, embora reconheça que a falta de respeito emerge de ambos os lados implicados na relação. Também há que se considerar que, apesar de se tratar de uma fala de um profissional médico, as colocações apresentadas não se referem a um grupo profissional específico, mas apresenta, de forma generalizada, o perfil das relações no que tange a grupos profissionais. Percebe-se que a falta de conhecimento sobre os diversos processos de trabalho em saúde contitui-se como um dos fatores que favorece a fragmentação do sistema de saúde. $\mathrm{Na}$ opinião do entrevistado, isto reverte-se em falta de respeito multilateral, com prejuízo da solidariedade entre as equipas e transformando-se em oposição e luta.

Diante disso, há que se considerar que a divisão do trabalho é um processo de interação social. Este 
processo ocorre à medida que os sujeitos envolvidos se engajam constantemente na tentativa de definir, estabelecer, manter e renovar as suas atividades. Mas também à medida que os sujeitos estão envolvidos nas próprias relações com os demais indivíduos, participantes nesse mesmo processo. Esta interação não se desenvolve de forma desarticulada do restante sistema e pode ser afetada, por exemplo, pelo poder relativo dos indivíduos na estrutura (Allen, 2000), como observado nos seguintes relatos: [...] aqui é daquela forma: manda quem pode, obedece quem tem juizo. Se bá alguma divergência entre algumas pessoas, não são escutadas ambas as partes. Geralmente, escuta a parte que tem um poder, assim, mais elevado aqui dentro, e essa parte é que fica. Então, é muito raro as pessoas terem, assim, a discussão: o que é que aconteceu? (AE8); Temos uma coordenação médica, extremamente fechada pra enfermeiro. Extremamente fechada. A relação aqui: quem pode manda, obedece quem tem juízo. (E5); [...] elas [as equipas] são bem separadas, tá? Assim, técnico com técnico, médico com médico, enfermeiro, enfermeira. [...] Eu, assim, me dou bem com todo mundo, independente do nivel que seja. Mas a gente sente, a gente vê, porque, às vezes, têm pessoas que, às vezes, passa quase por cima da gente, não tem coragem de dá nem um bom dia, né? (AE4). Nestas falas, chama a atenção, inicialmente, a heterogeneidade dos discursos, uma vez que há perceções bastante contraditórias sobre as relações profissionais constituídas na equipa. Isto coloca em evidência que a divisão e organização do trabalho abrangem interações sociais que interferem na própria forma de perceber a estrutura organizacional. Mas ao mesmo tempo, essa interação social pode ser constituída pelo poder relativo de cada sujeito no contexto das negociações possíveis e necessárias (Freidson, 1976). Se por um lado uma interação aponta para o entendimento de uma relação equilibrada, na qual se supõe uma partilha de responsabilidades, por outro, é possível analisar que, na estrutura de serviços de saúde, não há uma definição das funções e responsabilidades de cada profissional, o que acaba por ser definido contingencialmente, nas práticas quotidianas.

A forma de organização do trabalho, com equipas já estabelecidas, é um fator que favorece a divergência de perceção sobre o trabalho e as atividades desempenhadas por cada equipa. A maior parte das experiências vivenciadas quotidianamente acontece entre os profissionais de uma determinada equipe, sem, entretanto, abarcar relações quotidianas de troca de vivências entre as diferentes equipas. As divergências e convergências estão localizadas em microespaços e não generalizadas para todo o SAMU. Assim, nas entrevistas deste estudo, quando questionados quanto às relações entre os profissionais do SAMU, os entrevistados direcionavam as suas respostas para as relações da equipa na qual estavam inseridos, desconsiderando a possibilidade das relações da equipa abrangerem todos os profissionais. Dessa forma, ao analisar os discursos sob a ótica dos limites profissionais e das delimitações de território no trabalho do SAMU, enfrenta-se certa dificuldade em se considerar o grupo enquanto equipa de trabalho. Há, sim, uma noção de equipa em relação aos grupos que trabalham nas ambulâncias, mas também uma exclusão mútua dos demais grupos, ou equipas. Percebe-se também uma tendência a uma certa segregação por grupo profissional. Esse entendimento de uma instituição com várias equipas isoladas entre si favorece a fragmentação dos processos de trabalho. Estes são desenvolvidos de forma singular por cada grupo profissional, o que modifica as relações de poder e de trabalho. Cria, também, uma diversidade de limites profissionais, mesmo que entre grupos semelhantes, como médico-enfermeiro, enfermeiroauxiliar de enfermagem, entre outros, configurando as relações de poder dentro da própria equipa.

$\mathrm{Na}$ tentativa de compreender as relações entre os profissionais, é importante considerar que o poder não tem uma essência, mas é um atributo, onde os sujeitos dominantes são aqueles que, em determinado momento, o detém. Por outro lado, são dominados aqueles sujeitos sobre os quais o poder é exercido. O poder, então, é algo operatório, onde o conjunto das relações de força define as relações de poder (Deleuze, 2006). Entretanto, o entrevistado argumenta que [...] aqui é daquela forma manda quem pode, obedece quem tem juizo. Se há alguma divergência entre algumas pessoas não são escutadas ambas as partes, geralmente escuta a parte que tem um poder assim mais elevado aqui dentro e essa parte é que fica. Então é muito raro as pessoas terem, assim, a discussão: o que é que aconteceu?

A referência ao dito popular manda quem pode, obedece quem tem juizo remete-nos a uma estrutura organizacional onde certos indivíduos 
são, independente da situação, detentores de um poder absoluto. Sugere, ainda, a possibilidade do estabelecimento de um tipo de relação que se encerra com a submissão a uma determinação imposta, sem que surjam questões, argumentos ou resistência em relação ao poder exercido. Pensar essa possibilidade como real seria excluir o sujeito do próprio processo de trabalho, o que é inviável, uma vez que o sucesso organizacional perpassa a construção de sujeitos conectados com as demandas sociais em questão, bem como com as habilidades exigidas num determinado momento histórico (Marques, 2006). Assim, é importante considerar que, mesmo num cenário onde é negado ao sujeito o direito de manifestar claramente a sua resistência ao poder estabelecido, ele o fará através de outras ações.

Isso remete-nos à docilização dos corpos estudada por Foucault no século passado. Nessa perspetiva, trabalhar com indivíduos obedientes seria trabalhar com corpos docilizados ou bem adestrados, o que teria mais utilidade para as organizações. Assim, almeja-se o ajustamento cada vez mais controlado, numa lógica racional e económica, entre as atividades produtivas, as redes de comunicação e as relações de poder, na tentativa de adestrar os corpos (Dreyfus \& Rabinow, 1983). Neste aparato disciplinador, alguns detêm a maior fatia de poder e a outros cabe obedecer, seguir as normas, mesmo que exista o espaço da resistência.

$\mathrm{Na}$ análise do processo de trabalho do SAMU são observados alguns traços desta tentativa de docilização do trabalhador, que podem ser traduzidos pela proposta constante de cursos de atualização, da intensa utilização de protocolos clínicos, da descrição detalhada de rotinas de trabalho, enfim, de um aparato disciplinador eficiente. Dessa forma, com a utilização de dispositivos disciplinares que definem os atos com exatidão, pode-se hierarquizar, comparar, homogeneizar e excluir, numa relação mútua, os indivíduos "bons" e os "maus" (Foucault, 2008). Assim, o entrevistado menciona que [...] eu, principalmente, fico muito insatisfeita, às vezes, é com o sistema. A forma como ele é, né!? [...] Questão de... do outro não entender aquela forma como você trabalha. Às vezes, você também não entender a forma como o outro trabalha e ficar criando desavença. (M3).

O entrevistado refere a insatisfação para traduzir 0 seu sentimento diante da não-aceitação, por parte de colegas, em relação à forma de desenvolver as suas atividades. Ao mesmo tempo, o entrevistado assume que o facto de ele próprio não entender o trabalho do outro é motivo de desavença entre colegas. Transfere a sua responsabilidade para o sistema que é genérico, não personalizado e, por isso mesmo, mais difícil de ser atingido. Isto aponta para o reconhecimento, por parte dos próprios trabalhadores, da necessidade de haver uma regulamentação que defina a forma ideal de proceder nas atividades quotidianas do trabalho, como forma de aceitação no grupo. Mais do que isso, como estratégia de não exclusão social nas relações de trabalho.

Assim, embora a menção à docilidade e ao adestramento dos corpos (Foucault, 2008) possa parecer, na sociedade contemporânea, um jargão de teor pejorativo e ultrapassado, há que considerar que refletir sobre a sua essência é refletir sobre a realidade institucional de muitas organizações que, em diferentes graus, almejam um ideal de produtividade que consideram, como ponto central, que o controle e a disciplina dos corpos são instrumentos necessários para o alcance de resultados.

Isto não significa dizer que se tratam de estruturas que cultuam formalmente, nos seus desenhos organizacionais, a relação dominante-dominado. $\mathrm{Na}$ cultura ocidental e, particularmente na brasileira, a relação de dominação ainda não foi superada pelas pessoas que trabalham nas organizações, de forma que ainda é muito presente, nos comportamentos individuais, esse tipo de postura. Além disso, o trabalho na área da saúde traz consigo a relação de dominação e supremacia de alguns profissionais em relação a outros, como pode ser exemplificado pela supremacia do médico em relação aos demais componentes da equipa e do enfermeiro em relação aos demais profissionais da equipa de enfermagem, como expressam alguns profissionais: Ela [a relação] é difícil. São os famosos CRM's [referência ao registro no Conselho Regional de Medicina] aí, né? [...] Eles não respeitam, não. É um ou outro que respeita um todo, né? Mas a grande maioria, são arrogantes, tão acima de Deus, acima de lei, acima de tudo aqui. (C1);

Alguns [médicos] que querem, às vezes, sobrepor opiniões e obrigações aos técnicos de enfermagem. Nem muito aos enfermeiros, porque os enfermeiros estão sempre juntos com os médicos, nas USAs [Unidade de Suporte Avançado]. (M1); 
A relação do poder, mesmo, sobre o outro: Ab! Eu sou médico, eu mando. Ab! Eu sou bombeiro, eu tenbo supremacia sobre o SAMU, eu vou ficar. Não sei onde existe isso mais, não, né? (E6);

É, eu acho que o médico do SAMU tem muito, ainda, de arrogância, de prepotência, que ele precisa de perder, né? Nós de uma forma geral, os médicos do SAMU. (M2).

Os relatos refletem a histórica posição de dominação da classe médica sobre os demais profissionais de saúde, a qual é claramente reconhecida pelos próprios médicos. Os relacionamentos e o trabalho de construção das fronteiras profissionais que envolvem grupos de médicos com os demais profissionais de saúde têm sido alvo constante de preocupação e, considerando-se a natureza dinâmica do trabalho e da sua atuação nos cenários de atenção à saúde, provavelmente, essa relação continuará a sofrer constantes modificações (Allen \& Pilnick, 2005).

Assim, num primeiro momento de observação, a homogeneidade conferida à equipa do SAMU pelos uniformes idênticos de todos os profissionais que trabalham nas ambulâncias pode favorecer a noção de um grupo, também homogéneo, e com distribuição equilibrada de forças. Entretanto, essa ideia de relações muito equilibradas pode ser desconstruída quando se observa o Serviço mais de perto e mais detalhadamente. As relações quotidianas são marcadas de forma bastante expressiva pela constante necessidade da demarcação de territórios profissionais, o que se manifesta através de práticas que evidenciam a heterogeneidade vivenciada na luta por espaços profissionais.

Se por um lado, a forma como as relações profissionais acontecem é alvo de questões e críticas por muitos profissionais, por outro lado, é unânime, na fala de todos os entrevistados que mencionaram a relação com a Central de Regulação de Casos Médicos, a referência à sua precariedade. É interessante observar que os médicos que trabalham na regulação são os mesmos que trabalham nas ambulâncias, embora as críticas não se limitem a uma determinada classe profissional. De forma geral, a maior parte dos entrevistados relatam uma boa relação da equipa de trabalho, embora façam considerações pontuais a esse respeito, entretanto, sempre que discutida a questão da regulação, muitas são as queixas e as críticas endereçadas aos médicos reguladores.

Quem tá na rua, o médico, ele está com a gente na ambulância reclamando da regulação. Na semana seguinte, ele vem na regulação e faz a mesma coisa que reclamou que o cara fez com ele na semana anterior. Que enviou por uma coisa que não precisava. Todo mundo reclama de todo mundo [...]. (E5);

[...] tem uma central de regulação. É ela que decide aonde a gente vai, num vai. Então, às vezes, dá insatisfação da gente ir, às vezes, num atendimento que não seria prá gente. (E9);

Eu já cansei de sair na USA [Unidade de Suporte Avançado] aqui, prá ir junto com uma USB [Unidade de Suporte Básico] numa ocorrência que até então seria grave, que eles falaram na regulação. E chega lá não é nada daquilo que falaram. (AE8).

Estes discursos refletem a forma como o poder se estabelece e circula nas redes de relações, considerando que a configuração das relações de poder guarda estreita dependência com a posição ocupada pelos indivíduos na estrutura. O poder é transitório, circula e muda de mãos de acordo com as circunstâncias. O médico, na condição de regulador, detém poder de decisão sobre o que os outros profissionais, inclusive sobre o que os médicos das ambulâncias deverão fazer, quando o farão e com que recursos. Ao assumir a posição de médico de ambulância, o profissional assume, também, a condição de submissão ao colega regulador, tendo que acatar as suas decisões.

Entretanto, embora os médicos assumam as duas posições, de regulação e de atendimento nas ambulâncias, observa-se uma certa dificuldade em vislumbrar uma das posições estando na outra. Ou seja, quando está na rua não se percebe como eventual regulador, nem quando está na regulação consegue vislumbrar a sua atuação no atendimento in loco. Isso acaba por gerar uma falta de sensibilidade em relação ao colega no momento em que ele está numa posição diferente da posição do outro profissional e levantamento de questões sobre as decisões tomadas pelo médico regulador.

A satisfação pessoal com a atividade laboral pode ser um dos fatores associados a esse comportamento de levantamento de questões sobre as condutas dos colegas e manutenção de posturas semelhantes, uma vez que os médicos têm preferência por trabalhar nas ambulâncias, em vez de ficarem restritos a uma sala, com a função de atender telefonemas e de tomar decisões, sem ter oportunidade de avaliar, de 
facto, o paciente que faz a solicitação. Isto pode ser exemplificado pela seguinte fala: É mesmo a coisa da adrenalina. Às vezes, é muito alta e, às vezes te causa uma tensão excessiva. É, aqui na central de regulação então, você tem muitas... Como é que eu vou dizer? Muito volume de atendimento prá uma pessoa só, entendeu? (M1).

Também é motivo de insatisfação o facto de um único médico regulador atender um grande volume de solicitações, o que lhe obriga a trabalhar, durante todo o tempo, sob elevada tensão e com uma diversidade de situações simultâneas. Além disso, como demonstrado na fala do entrevistado, os médicos, em muitas situações, não estão completamente preparados para atuarem como reguladores uma vez que os currículos dos cursos de medicina, não disponibilizam, dentre as suas disciplinas, conteúdos que contemplem esse tipo de atendimento. [...] porque isso [regulação médica] a gente não tem na faculdade, o atendimento pré-hospitalar. Nós não temos regulação. Como fazer, né? Diagnóstico dado pelo telefone, tudo, e a gente é colocado no sistema sem um treinamento, sequer, prévio. Eu já falei isso. Já falei isso com a coordenação também, que eu acho que isso é muito falbo. (M3).

Se na estrutura interna do SAMU ainda são muitos os desafios na procura de relações profissionais mais harmoniosas e menos conflituosas, quando a análise dessas relações alcança os profissionais dos demais níveis assistências a sua complexidade multiplica-se. Embora haja uma referência a um sentimento de pouca simpatia dos trabalhadores de outros serviços de saúde pelo SAMU, de maneira geral, nos discursos analisados, sobressai o desconforto dos profissionais com as relações estabelecidas com as Unidades de Pronto Atendimento (UPA). Este relacionamento é classificado como mau, principalmente por perceberem que há, por parte dos profissionais das UPA's, um entendimento de que o SAMU é responsável pelo aumento do volume de trabalho daquelas Unidades.

Isso [a relação com outros serviços] é muito mais problemático, porque existe certo, é... Principalmente das UPAs, hospitais, certa... Ninguém gosta do SAMU, né? Porque o SAMU leva os problemas prá eles. (M1). Entretanto, o mesmo entrevistado aponta outra razão que pode estar associada aos conflitos entre os dois serviços. Trata-se da própria legislação brasileira de atendimento às urgências, que define o SAMU como Vaga Zero, ou seja, qualquer serviço de saúde tem que disponibilizar vagas para receber pacientes transportados por ele, independente da sua disponibilidade, a priori (Portaria no 2.048/GM-MS de 5 de Novembro, 2002). Entretanto, o maior problema não está na legislação propriamente dita, mas nas reações que ela provoca nos diferentes Serviços de saúde. Assim, o profissional do SAMU considera que a legislação deveria abrir as portas por si só.

A gente não teria nem que pedir prá entrar. A gente tem que chegar e entrar. Aí, a gente ainda faz contato, ainda faz tudo isso. A gente tenta dialogar. (M1).

O discurso acima mostra a perceção de superioridade do profissional do SAMU no que se refere ao seu relacionamento com outros serviços de saúde. Observa-se que o profissional considera o contacto com a Unidade que receberá o paciente transportado uma gentileza adicional e não uma obrigação. Além disso, o profissional tem dificuldade de perceber que, na verdade, diante da imposição da vaga-zero pela Portaria 2.048 (Portaria no 2.048/GM-MS de 5 de Novembro, 2002), a possibilidade de diálogo colocase de forma bastante restrita, uma vez que a resposta às solicitações do SAMU deve ser sempre positiva.

\section{Conclusão}

Considerando-se a ubiquidade das relações de poder, a sua análise no contexto do SAMU constituiu-se num elemento importante para a compreensão do seu papel nas relações estabelecidas. A análise das relações entre os profissionais permitiu uma melhor compreensão das estratégias empregadas na contenção dos seus efeitos e da forma como os profissionais se posicionam nas suas práticas quotidianas, na tentativa de se colocarem de forma mais confortável na rede de relações.

Também foi possível perceber o movimento circular que o poder assume nas práticas dos profissionais do SAMU. Embora exista uma estrutura formal bem definida e reconhecida pelos trabalhadores do Serviço, as relações assumem amplitude e complexidade que extrapolam esses limites formalmente estabelecidos, o que evidencia tensões que emergem nas práticas quotidianas.

A compreensão das tensões próprias das práticas no SAMU implica a procura de respostas a questões que 
possam esclarecer como essas práticas são organizadas em determinado contexto. Para os profissionais do SAMU, é difícil identificar os tênues limites entre o seu espaço de trabalho e o dos outros, uma vez que o seu próprio espaço corresponde ao território de toda a cidade de Belo Horizonte e tentar delimitá-lo é mais um desafio a ser enfrentado. Esse desafio é maximizado pela fragmentação interna e externa dos serviços de saúde, ou seja, a deficiência de trabalho em rede que esses serviços possuem. Assim, o que se observa é a exacerbação de conflitos, os quais favorecem ações individualistas que prejudicam a proposta de integração do sistema de saúde e que geram situações que comprometem o ambiente de trabalho das equipas de saúde de forma generalizada. Embora este estudo tenha sido realizado no contexto da atenção pré-hospitalar brasileira, a complexidade das relações de poder constituídas neste Serviço, bem como as dimensões práticas alcançadas por essas relações ao longo da estrutura podem subsidiar reflexões sobre outros cenários. Além disso, considerando a complexidade do SAMU de Belo Horizonte, será ainda necessário o desenvolvimento de outros estudos que possam ampliar a compreensão desse fenómeno, e que venham a complementar as discussões até ao momento apresentadas.

\section{Referências bibliográficas}

Allen, D. (2000). Doing occupational demarcation: The "boundary-work" of nurse managers in a district general hospital. Journal of Contemporary Ethnography, 29(3), 326-356.

Allen, D., \& Pilnick, A. (2005). Making connections: Healthcare as a case study in the social organization of work. Sociology and Health \& Ilness, 27(6), 683-700.

Capelle, M. C., Melo, M. C. O. L., \& Gonçalves, C. A. (2003). Análise de conteúdo e análise de discurso nas ciências sociais.
Revista de Administração da UFLA, 5(1), 69-85.

Cruz, S. G., \& Ferreira, M. M. F. (2012). Perceção da cultura organizacional em instituições públicas de saúde com diferentes modelos de gestão. Revista de Enfermagem Referência, 3(6),103-112.

Deleuze, G. (2006). A new cartographer discipline and punish. In G. Deleuze, Foucault (pp. 21-38). London, England: Continuum.

Dreyfus, H. L., \& Rabinow, P. (1983). Michel Foucault: Beyond structuralism and bermeneutics (2nd ed.). Chicago, IL: University of Chicago Press.

Durkheim, E. (2008). Da divisão do trabalbo social (3a ed.). São Paulo, Brasil: Martins Fontes.

Fairclough, N. (2006). Discourse and social change (11nd ed.). Cambridge, England: Polity Press.

Foucault, M. (2008). Vigiar e punir: História da violência nas prisões (35 ed.). Petrópolis, Brasil: Vozes.

Freidson, E. (1976). The division of labor as social interaction. Social Problems, 3(23) 304-313.

Marques, A. A. M. (2006). O conceito de poder em Foucault: Algumas implicações para a teoria das organizações. In Anais do $3^{\circ}$ Congresso Virtual Brasileiro de Administração. Recuperado de http://www.comvibra.com.br/2006/ artigos/74_pdf

Mckee, M., Dubois, C. A, \& Sibbald, B. (2006). Changing professional boundaries. In C. A. Dubois, M. McKee, \& E. Nolte (Eds.), Human resources for health in Europe (pp. 63-78). Berkshire, England: Open University Press.

Miles, M., \& Huberman, M. (1994). Qualitative data analysis: An expanded sourcebook (2nd ed.). London: Sage.

Minayo, M. C. S. (2004). O desafio do conbecimento (11ª ed.). São Paulo, Brasil: Hucitec.

Portaria n ${ }^{0}$ 2.048/GM-MS de 5 de Novembro (2002). Regulamento técnico dos Sistemas Estaduais de Urgência e Emergência. Ministério da Saúde, Brasil.

Resolução no 196 de 10 de Outubro (1996). Diretrizes e normas regulamentadoras de pesquisa envolvendo seres humanos. Conselho Nacional de Saúde, Ministério da Saúde, Brasil. 
